\title{
Effect of Aqueous Minerals Supplementation on Growth and Survival of Litopenaeus vannamei in Low Salinity Water
}

\author{
E. Nehru ${ }^{1 *}$, A. Chandrasekhara Rao ${ }^{2}$, D. Pamanna ${ }^{2}$, P. Ranjith ${ }^{1}$ and B. Lokesh ${ }^{2}$ \\ ${ }^{1}$ Fisheries Field Officer, Telangana, India \\ ${ }^{2}$ College of Fishery Science, Sri Venkateswara Veterinary University, Muthukur, Nellore, \\ Andhra Pradesh-524344, India \\ *Corresponding author
}

\section{A B S T R A C T}

\begin{tabular}{|l|}
\hline K e y w o r d s \\
$\begin{array}{l}\text { Aqueous minerals, } L . \\
\text { vannamei, Growth, } \\
\text { Survival, Low salinity }\end{array}$ \\
\hline Article Info \\
\hline $\begin{array}{l}\text { Accepted: } \\
\text { 14 December } 2017 \\
\text { Available Online: } \\
\text { 10 January } 2018\end{array}$ \\
\hline
\end{tabular}

Keywords

Aqueous minerals, $L$. vannamei, Growth,

\section{Introduction}

The culture of shrimp and other fish and crustaceans using low salinity water is a trend that continues to grow throughout the world. In 2011, aquaculture accounted for $52.5 \%$ of the world's fish food supply (FAO 2011). Most fish, crustacean and mollusc aquaculture production $(61 \%)$ occurs in inland waters. In the same year, brackish water production accounted for $8 \%$.

In most locations throughout the world the primary candidate of choice for shrimp culture in low salinity water is the Pacific white shrimp, Litopenaeus vannamei, which is native to the Pacific coast from Northern Peru to Mexico. In 2011, L. vannamei production worldwide was close to 2.5 million tonnes, which is roughly $71 \%$ of total shrimp and prawn production worldwide (FAO 2011). All indications are that the production of $L$. vanname $i$ will continue to expand, particularly in countries such as China, Vietnam and Thailand. The Pacific white shrimp is a euryhaline species that can tolerate a wide range of salinities $0.5-45 \mathrm{~g} \mathrm{~L}-1$ (Menz and Blake, 1980). The remarkable ability of $L$. vannamei to grow in less than ideal environments has made it the species of choice for culturing in low salinity water (Alday-Sanz, 2010). 
The success of many farmers in rearing shrimp in low salinity environments, variable growth and survival among ponds are still being reported on a regular basis (Roy et al., 2009a). The problem is compounded by the fact that no low salinity water is the same with large variations in source, salinity, and ionic profile being reported (Boyd and Thunjai, 2003). While it is suspected that some of the "mortality" and variability is due to stocking errors, environmental factors, and farm management, there is sufficient evidence to suggest that less than ideal ionic profiles are indeed responsible for much of the observed mortality (Roy et al., 2007a).

In order to improve growth, survival, and production of shrimp reared in low salinity water two different strategies have been employed by researchers and farmers. These strategies include water modification approaches which alter the low salinity rearing medium to make it more acceptable for production of shrimp and nutritional strategies that focus on modification of diets offered to shrimp, usually with supplements that provide an osmoregulatory advantage at low salinity.

A dietary source of 23 minerals has been demonstrated as essential in 1 or more animal species. These elements are divided into two groups: the 7 macro minerals (calcium, chlorine, magnesium, phosphorus, potassium, sodium, and sulphur) and 16 trace minerals (aluminium, arsenic, cobalt, chromium, copper, fluorine, iodine, iron, manganese, molybdenum, nickel, selenium, silicon, tin, vanadium, zinc). Thirteen minerals are required in the diet of most terrestrial animals and may be essential for aquatic animals. Among these minerals, eight are cations: calcium $\left(\mathrm{Ca}^{2+}\right)$, copper $\left(\mathrm{Cu}^{2+}\right)$, iron $\left(\mathrm{Fe}^{2+}\right)$, magnesium $\left(\mathrm{Mg}^{2+}\right)$, manganese $\left(\mathrm{Mn}^{2+}\right)$, potassium $\left(\mathrm{K}^{+}\right)$, sodium $\left(\mathrm{Na}^{+}\right)$, and zinc $\left(\mathrm{Zn}^{2+}\right)$; and five anions or are usually found in anionic groupings: chloride $\left(\mathrm{Cl}^{-}\right)$, iodine $\left(\mathrm{I}^{-}\right)$, molybdenum $\left(\mathrm{Mo}^{2-}\right)$, phosphate $\left(\mathrm{PO}^{43-}\right)$ and selenite $\left(\mathrm{SeO}^{32-}\right)$ (Scott et al., 1982).

Since aquatic animals can obtain minerals from both ambient water and feed, dietary supplements of selected minerals could facilitate better survival and growth of shrimp held in low salinity conditions.

The present study was aimed to observe the mineral supplementation on growth and survival of L. vannamei in low salinity water.

\section{Materials and Methods}

The experiment was conducted in Wet Laboratory of the Department of Aquaculture, College of Fishery Science, Sri Venkateswara Veterinary University, Muthukur, for a period of 7 weeks. Litopenaeus vannamei (1000 numbers) were obtained from CP Hatchery, Nellore, who has been authorized by Coastal Aquaculture Authority (CAA), Chennai to produce seed. Post larvae (PL10) transported by road in plastic bags containing $15 \mathrm{ppt}$ saline water. PL transferred to the same salinity water in the wet lab. Acclimatization was carried out over 8 days. During this time salinity was lowered from $15 \mathrm{ppt}$ to $3 \mathrm{ppt}$ bore well water at an average rate of $4 \mathrm{ppt} \mathrm{day}^{-1}$ (Araneda et al., 2008). During this period the seed were fed with control diet.

\section{Experimental design}

The aquarium tanks used for experiments were of size $60 \times 30 \times 30 \mathrm{~cm}$. Twenty one aquariums were stalked on iron racks. Aquariums were located in a secured place where there is no direct sunlight and covered all the sides with black paper to avoid algal growth in the tank. Water in the aquariums was aerated by using air stones connected to the air compressor. Filters are used for filtering the aquarium water. The underground water was taken into a tank and allowed to aerate for 48 hours and 
was used for filling the aquaria. Salinity was checked before taken the water into aquarium. The water is allowed to filter for 24 hours before introducing the shrimps into the aquaria.

Ten numbers of Shrimps with initial average weights of $0.15-0.18 \mathrm{gm}$ were introduced in to each aquarium and triplicates were maintained for each treatment (Aqueous supplementation of K-20mg and K-30mg, Mg$40 \mathrm{mg}$ and $\mathrm{Mg}-80 \mathrm{mg}$ ) includes control. Regular water exchange of $25 \%$ was done every day. Left over feed, excreta and other debris were siphoned off from the bottom of the tank without disturbing the shrimps.

\section{Experimental feed preparation and Feeding}

In the experiment, formulated feed with the crude protein (35\%) were used for feeding. Fishmeal, soybean meal, groundnut oil cake, maize and deoiled rice bran were the ingredients used for control feed. Experimental diets were prepared with same ingredients as used in control diet. All the ingredients used in feeds were obtained from local markets. Ingredients used in the feeds were estimated for proximate composition (AOAC, 1995) (Table 1).

Each ingredient was procured in required quantity and ground into powder and sieved. All the ingredients were then mixed in required proportion and water was added at the rate of $30 \mathrm{ml}$ per every $100 \mathrm{~g}$ of feed and dough was prepared. Maida (1\%) was used as a binding agent in the feed. The dough was cooked for 20 minutes in pressure cooker and then cooled. 1\% Vitamin mixture was added. The homogenous dough was pressed through a hand pelletizer (La Monferrina s.r.l, Italy) with a sieve of $1 \mathrm{~mm}$ diameter. The feed was dried in shade and then in hot air oven at 80$90^{\circ} \mathrm{C}$ to reduce the moisture content to $10 \%$ and stored properly in dry and air tight bottles and kept in dark cool place.

\section{Growth performance}

The growth parameters of all the shrimps of each aquarium were individually estimated by taking their total body length and weight at 7 days interval. Individual shrimp length and weight were recorded. Individual shrimp weight gain, specific growth rate (SGR) and feed conversion ratio (FCR) was assessed using the following formulae:

Weight gain $(\%)=(F W-I W) \times 100 / I W$,

FCR $=$ Feed given (DW) $/$ body weight gain (WW),

$\operatorname{SGR}(\%)=[\ln (\mathrm{FW})-\ln (\mathrm{IW}) /[\mathrm{N}] \times 100$.

Where FW = final weight, IW = initial weight, $\mathrm{DW}=$ dry weight, $\mathrm{WW}=$ wet weight, $\ln =$ natural $\log$ and $\mathrm{N}=$ number of culture days

\section{Survival rate}

Survival of the shrimps at each fort-night was noted down and survival rates are calculated.

\section{Statistical analysis}

Statistical analyses were performed using web agristat package (WASP) version 2.0. The data obtained on Growth, Survival and Food Conversion Ratio was statistically analyzed by applying Randomized Block Design (RBD) of two-way classification.

\section{Results and Discussion}

Growth of L. vannamei supplied with aqueous minerals

Weight of shrimp in grams and weight increment data observed weekly for different treatments were presented in figures 1 and 2 . An overall study indicated that the K-20mg recorded total weight increment of $3.64 \pm 0.05 \mathrm{~g}$ 
in the 49 days experimental period. This was followed by the $\mathrm{Mg}-40 \mathrm{mg}$ ( $3.30 \pm 0.05)$, K$30 \mathrm{mg}(3.28 \pm 0.07 \mathrm{gm})$ they stood in second and third positions respectively.

Specific growth rates of $L$. vannamei supplied with aqueous minerals supplementation

Specific growth rates for L. vannamei treated with different diets were calculated and presented in figure 3 . The specific growth rates by end of the experimental period ( 49 days) were calculated for all treatments. Control group has the lowest Specific Growth Rate of $6.03 \%$. The highest value was in $\mathrm{K}$ $20 \mathrm{mg}$ with $6.50 \%$. The treatments that stood second and third positions were $\mathrm{Mg}-80 \mathrm{mg}$ (6.38\%) and $\mathrm{Mg}-40 \mathrm{mg}$ (6.17\%). These were followed by, K-30mg (6.16\%).

\section{Feed conversion ratio of $L$. vannamei with aqueous minerals supplementation}

The Feed Conversion Ratio in different experiments of $L$. vannamei groups were calculated and presented in figure 4 . The range for Feed Conversion Ratio observed during the period of experiment was $0.21(\mathrm{~K}-20 \mathrm{mg})-$ 3.68 (control).

The Feed Conversion Ratio was subjected to analysis of variance (ANOVA) and treatments found to be non-significant.

\section{Survival of $L$. vannamei supplied with aqueous minerals}

Survival percentages of $L$. vannamei shrimp in various experimental treatments are presented in figure 5. The survival percentage throughout the period of experiment was lowest in the control and all treatments. The treatment K-30mg had shown highest survival rate when compared to the other treatments.
The subsequent positions were occupied by Treatments K-30mg, Mg-80mg, Mg-40mg, K$20 \mathrm{mg}$ followed by control.

Treatment K-30mg has shown significant difference from all other treatments. There was significant difference in between experimental period also.

As the production of shrimp in inland low salinity waters continuous to expand, so does the need for cost effective methods for increasing the availability of essential ions to the organisms in order to ensure proper growth and survival.

Traditional practices, such as the application agricultural fertilisers (k-mag and murate of potash), commercial mineral mixtures application directly to the water without knowing the demand of shrimp, have been proven effective at improving growth and survival (Mc Nevin et al., 2004).

However, the use of these minerals needs to be optimised based on demand of the aquatic organism rather than dumping them in to the pond. It may either allow reduction in the level of supplementation of these minerals and also the risk of mortality of the animals.

Experiments in the present study were concluded at a salinity of $3 \mathrm{ppt}$, which is comparable with the salinity utilised by commercial shrimp farms where the bore wells are the basic source of water.

Maintenance of sodium, potassium and magnesium is necessary for proper physiological functioning of body, osmoregulation, building of body and also as activities for many enzymes which play role in carbohydrate metabolism and protein synthesis (Davis et al., 2005). 
Table.1 Proximate compositions of the various ingredients used in formulate feeds

\begin{tabular}{|l|l|l|l|l|l|l|}
\hline S. No & Ingredients & Moisture \% & $\begin{array}{l}\text { Crude } \\
\text { protein \% }\end{array}$ & $\begin{array}{l}\text { Crude } \\
\text { Fat \% }\end{array}$ & $\begin{array}{l}\text { Crude } \\
\text { Fiber \% }\end{array}$ & Ash \% \\
\hline $\mathbf{1}$ & Fish Meal & 8.60 & 58.10 & 10.00 & 0.30 & 19.20 \\
\hline $\mathbf{2}$ & Soya bean meal & 10.80 & 38.00 & 5.90 & 1.30 & 5.30 \\
\hline $\mathbf{3}$ & Groundnut oil cake & 6.00 & 37.70 & 13.80 & 13.20 & 7.30 \\
\hline $\mathbf{4}$ & Deoiled rice bran & 7.20 & 12.10 & 1.30 & 15.20 & 23.80 \\
\hline $\mathbf{5}$ & Maize & 15.90 & 8.00 & 4.80 & 1.10 & 1.40 \\
\hline
\end{tabular}
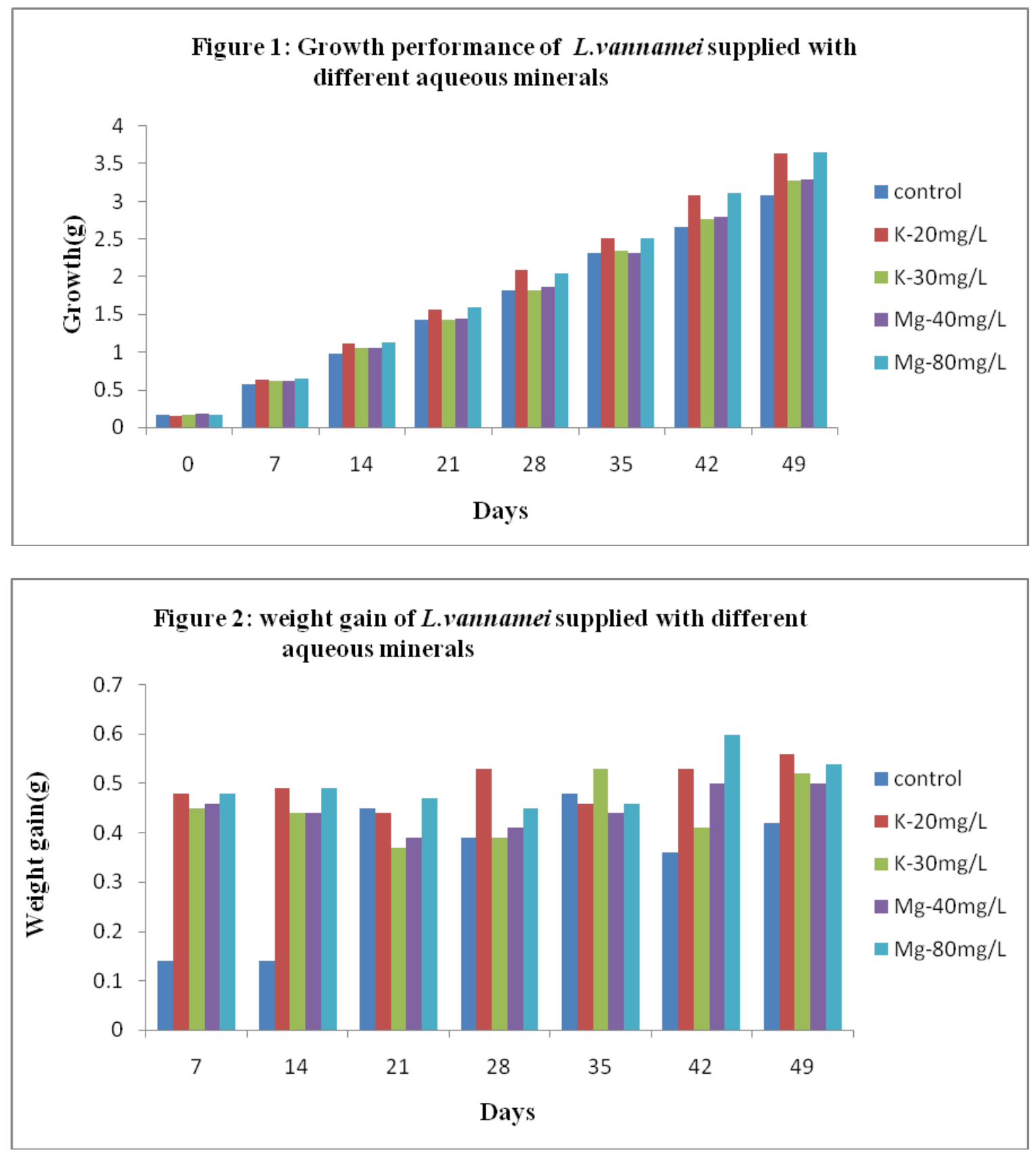

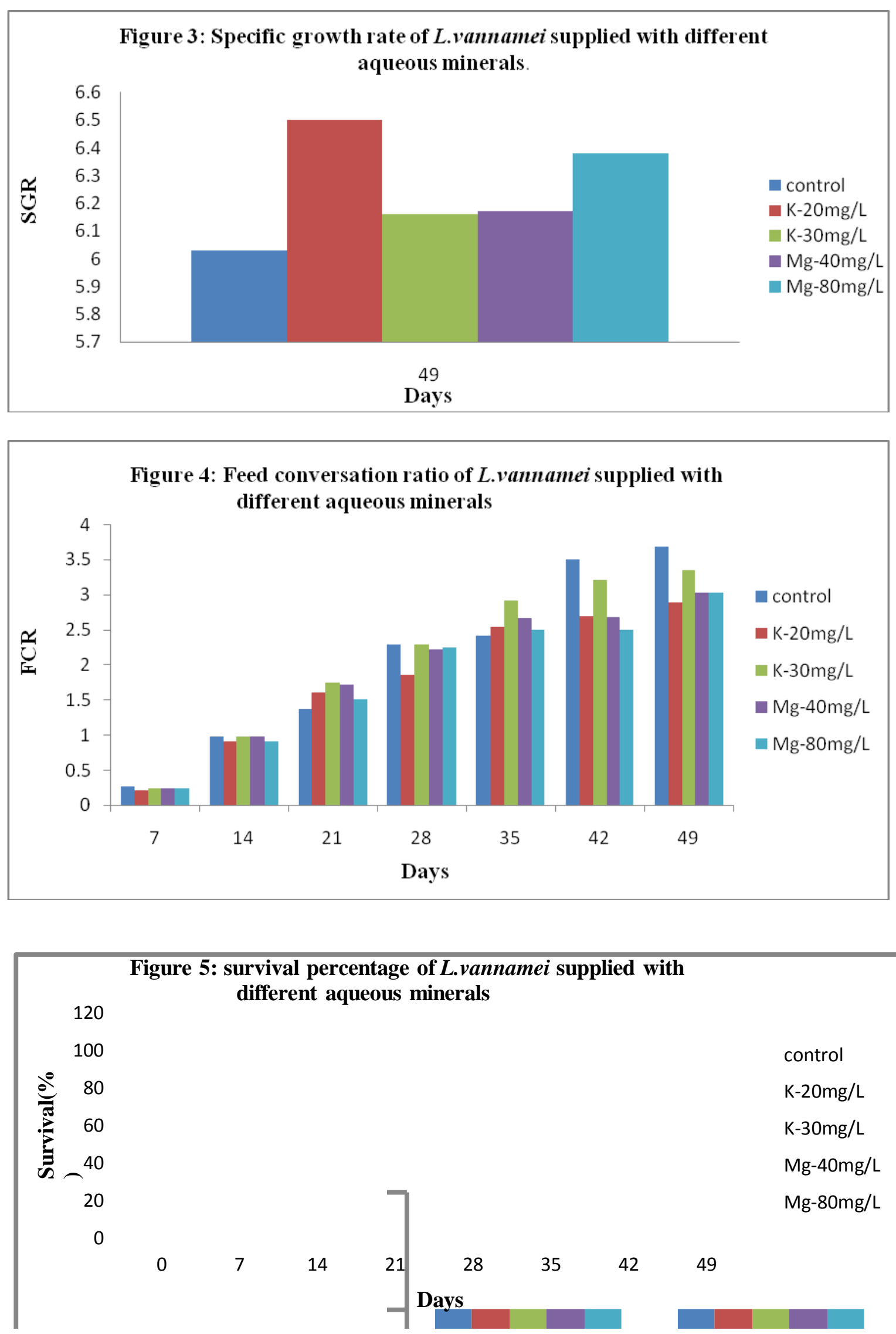

Figure 5: survival percentage of L.vannamei supplied with different aqueous minerals

120

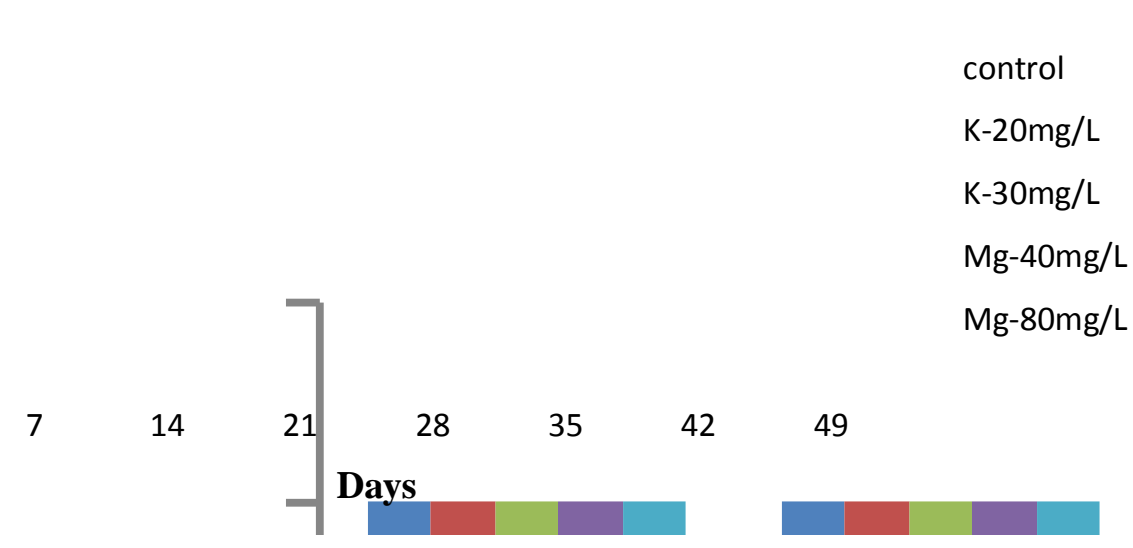




\section{Growth of $L$. vannamei in aqueous minerals supplementation}

Aquatic organisms collect most of their required mineral content from the surrounding water. In present study results indicated that the significant $(\mathrm{p}<0.05)$ increase in growth, lower FCR and higher specific growth rate at aqueous potassium supplementation $20 \mathrm{mg}^{-1}$ than to that of control diet. Individual weight gain and specific growth rate and percent weight gain were increased with increasing potassium concentration in aqueous source utilized in L. vannamei culture in low salinity waters (Roy et al., 2007a). However, in the present study weight gain, specific growth rate and feed efficiency were not increased with the increase of concentration of potassium supplementation from $20 \mathrm{mg}^{-1}$ to $30 \mathrm{mg} \mathrm{l}^{-1}$. Pragnell and Fotedar (2005) found that Penaeus latisulcatus reared in low salinity well water with $100 \%$ and $80 \%$ potassium concentration as compared to sea water resulted in slower growth.

Even though potassium concentration increased weight gain was not observed, it may be due to higher aqueous potassium concentration in shrimp tissue water decreases and the concentration of free amino acids in the tissue increases. With the progression of above process animal undergo stress it might have resulted in weight loss. Addition of magnesium to the water from $40 \mathrm{mg}^{-1}$ to $80 \mathrm{mg}^{-1}$ increased growth and specific growth rate. Roy et al., (2007a) also noticed similar growth increase in $L$. vannamei low salinity culture with magnesium addition from $10 \mathrm{mg} \mathrm{l}^{-1}$ to $160 \mathrm{mg} \mathrm{l}^{-1}$. Ahmad Ali (1999) was noticed suppressed growth with the magnesium addition in diet in Penaeus indicus. He was opined that the magnesium requirement might be satisfied through absorption from the water. However, feed efficiency did not show significant difference with the magnesium addition to the water.
Survival of L. vannamei in aqueous minerals supplementation

The results of the present study showed that aqueous potassium supplementation is necessary for the survival of $L$. vannamei in low salinity water culture. The shrimps have shown higher survival at the addition of potassium $30 \mathrm{mg} \mathrm{l}^{-1}$ to the water. Roy et al., (2007a) were observed similar increase in survival of $L$. vannamei with the increase of $\mathrm{K}^{+}$in the water. Zhu et al., (2004) were observed improper $\mathrm{Na} / \mathrm{K}$ ratio in low salinity water made significant impact on survival of L. vannamei. Pragnell and Fotedar, (2005) were reported that the potassium deficiency in low salinity water culture reduce the $P$. latisulcatus survival. Results in the present study indicated that addition of magnesium as aqueous source to the L. vannamei culture in low salinity water enhanced the survival of shrimp.

In the present study results showed increasing trend in survival with the increase of magnesium addition to the water. Our observation in the present experiment are also in agreement with previous studies evaluating the impact of magnesium and other minerals supplementation on survival of $L$. vannamei in low salinity waters (Davis et al., 2005 and Roy et al., 2007a). However, Roy et al., (2007a) observed increase of survival in $L$. vannamei in low salinity water up to $40 \mathrm{mg}^{-1}$ of magnesium supplementation to the water, further addition of magnesium resulted in decrease of survival.

It can be concluded that the aqueous minerals supplementation enhances the growth and survival of L. vannamei in low salinity water.

\section{Acknowledgement}

The authors are thankful to Dr. Manmohan Singh, Vice-Chancellor, SVVU, Tirupati for 
providing vital facilities to carry out this work. The SVVU, MFSc fellowship granted to the first author, is gratefully acknowledged.

\section{References}

Ahmad Ali, S. 1999. Calcium, Phosphorus and Magnesium Requirements in the Diet of shrimp Penaeus indicus. Asian Fisheries Science 12(1999):145-153.

Alday-Sanz, V. 2010. The Shrimp Book: Theory and Practice of Penaeid Aquaculture. Nottingham University Press, Nottingham.

AOAC. 1995. Official Methods of Analysis of the Association of Official Analytical Chemists. Washington, Dc. pp.101.

Araneda, M., Perez, E.P., Gasca-Leyva, E. 2008. White shrimp Penaeus vannamei culture in freshwater at three densities: condition state based on length and weight. Aquaculture 283: 13-18.

Boyd, C.E. and Thunjai, T. 2003. Concentrations of major ions in waters of inland shrimp farms in China, Ecuador, Thailand, and the United States. Journal of the World Aquaculture Society 34, 524-532.

Davis, D.A., Saoud, I.P., Boyd, C.E., Rouse, D.B. 2005. Effects of potassium, magnesium, and age on growth and survival of Litopenaeus vannamei postlarvae reared in inland low salinity well waters in west Alabama. Journal of the World Aquaculture Society 36: $403-$ 406.

FAO (Food and Agriculture Organization of the United Nations) 2011. Year book of Fisheries Statistics 2007. FAO Fisheries and Aquaculture Department. Food and Agriculture Organization of the United Nations, Rome.

McNevin, A.A., Boyd, C.E., Silapajarn, O., Silapajarn, K. 2004. Ionic supplementation of pond waters for inland culture of marine shrimp. Journal of the World Aquaculture Society 35: 460-467.

Menz, A., Blake, B.F. 1980. Experiments on the growth of Penaeus vannamei Boone. Journal of Experimental Marine Biology and Ecology 48: 99-111.

Roy, L.A., Davis, D.A., Saoud, I.P., Henry, R.P. 2007a. Effects of varying levels of aqueous potassium and magnesium on survival, growth, and respiration of the Pacific white shrimp, Litopenaeus vannamei, reared in low salinity waters. Aquaculture 262: 461-469.

Roy, L.A., Davis, D.A., Whitis. G.N. 2009a Pond-to-pond variability in post-larval shrimp, Litopenaeus vannamei, survival and growth in inland low salinity waters of west Alabama. Aquaculture Research 40: 1823-1829.

Scott, M.L., Nesheim, M.C., Young, R.J. 1982. Nutrition of the chicken. New York: M.L. Scott and Associates (1982).

Zhu, C., Dong, S., Wang, F., Huang, G. 2004. Effects of $\mathrm{Na} K$ ratio in seawater on growth and energy budget of juvenile Litopenaeus vannamei. Aquaculture 234: 485-496.

\section{How to cite this article:}

Nehru, E., A. Chandrasekhara Rao, D. Pamanna, P. Ranjith and Lokesh, B. 2018. Effect of Aqueous Minerals Supplementation on Growth and Survival of Litopenaeus vannamei in Low Salinity Water. Int.J.Curr.Microbiol.App.Sci. 7(01): 1706-1713. doi: https://doi.org/10.20546/ijcmas.2018.701.206 